\title{
Influence of Nozzle Height on Water Mist Fire Extinguishing System in Railway Tunnel Rescue Station
}

\author{
Peng Luo1, a, Wan Fu Liu¹, Wei Ping Han², Jian Jun Xia² and Kai Yao' \\ ${ }^{1}$ Tianjin University of Commerce, Tianjin 300134, China \\ ${ }^{2}$ Tianjin Fire Research Institute of MPS, Tianjin 300381, China
}

a291673428@qq.com

\begin{abstract}
Keywords: railway tunnel rescue station, water mist, nozzle height, heat release rate
Abstract. In order to study the fire extinguishing performance of fixed water-mist fire extinguishing system in railway tunnel rescue station, a water-mist fire extinguishing system is arranged in the tunnel model with length of $30 \mathrm{~m} \times$ width $6 \mathrm{~m} \times$ high $6 \mathrm{~m}$. According to the actual railway tunnel top of the laying of $25 \mathrm{kV}$ high-voltage power cable, water-mist nozzle installation can only be installed in the side and the characteristics of oil transport trains. On the installation of both sides of the tunnel height of $1.5 \mathrm{~m}$ and $4.5 \mathrm{~m}$ at the water mist nozzle were fire test, comparative extinguishing effect and cooling effect, and provide reference for the related engineering application of setting the water-mist fire extinguishing system in the railway tunnel rescue station.
\end{abstract}

\section{Introduction}

Water mist as the current developed countries recognized the best halon fire extinguishing agent alternatives [1], high extinguishing efficiency, water conservation, environmental friendliness and so on $[2,3]$, was applied to the railway tunnel rescue station. Water mist is an important facility for train fire suppression in railway rescue station, mainly through the hand-held water mist gun way to extinguish the fire on the train parts of the fire. However, the train fires in the railway tunnel rescue station have typical tunnel fire characteristics, such as large smoke, low visibility, and high temperature [4]. Therefore, in such a harsh environment, the way people directly intervene is difficult to play an effective fire extinguishing effect. Fixed water mist fire extinguishing system, the most dominant advantage is to reduce staff intervention, personnel do not need to be directly close to the train, with a fixed pipe network system to fight the train fire. Fixed water mist fire extinguishing system is the most prominent advantage is to reduce staff intervention, personnel do not need to be directly close to the train, with a fixed pipe network system to extinguish the fire. Not only reduces the direct intervention of the staff, but also to overcome the water mist gun can only extinguish disadvantage of portion fires.

\section{Water Mist Role}

The functions of water mist include fire extinguishing, cooling and attenuating thermal radiation [5-8]. Fire extinguishing effect is mainly through the fire source of the cooling and suffocation effect to achieve. When the water mist arrives near the fire source, it will evaporate and absorb a large amount of heat, thus reducing the flame temperature in the burning area. At the same time, because the water mist absorbs a large amount of heat, the volume will expand rapidly and dilute the oxygen concentration in the combustion zone, resulting in a significant reduction in oxygen concentration around the fire source. When the flame temperature drops to the limit or the oxygen concentration is low enough to keep the combustion burning, the flame will go out. The cooling effect is mainly achieved by the cooling of the water mist to the surrounding environment. When the heat absorption rate of the water mist on the surface of the object is greater than the thermal feedback rate of the flame to the surrounding object surface, the temperature of the surrounding object will gradually decrease. The role of attenuation of thermal radiation is mainly through the water mist and its evaporation of water vapor generated in the flame around the formation of thermal barriers to achieve. The barrier 
not only effectively reduces the radiant heat the flame, but also reduces the evaporation and pyrolysis rate of the combustion surface and the rate of fire spread. From a macro point of view, whether or not to extinguish the fire, the attenuation of the water mist on the radiation can protect the target and personnel from thermal radiation damage [9].

\section{Introduction of Experimental Platform}

Experimental Bench Layout. The experimental platform is a tunnel model with a length of $30 \mathrm{~m}$, a width of $6 \mathrm{~m}$ and a height of $6 \mathrm{~m}$. On this basis, the design of the water mist fire extinguishing system is carried out. Water mist nozzle spacing with reference to the "Technical Specification for Water mist Fire Extinguishing System" [10], the spacing is set to $3 \mathrm{~m}$. Refer to the length of each type of car and the nozzle spacing, the length of a single protected area as $12 \mathrm{~m}$, so 8 water mist nozzles should be arranged in a single protected area. Considering the $25 \mathrm{kV}$ high voltage power cable at the top of the railway tunnel, the water mist nozzle can only be installed in the side. So on the side, the water spray nozzles are respectively arranged at a height of $1.5 \mathrm{~m}$ and $4.5 \mathrm{~m}$, with 8 in each group. The total flow rate of the system is $220 \mathrm{~L} / \mathrm{min}$, the pressure at the end of the nozzle is $10 \mathrm{MPa}$. System spray intensity of about $3.05 \mathrm{~L} /\left(\mathrm{min} \cdot \mathrm{m}^{2}\right)$, are greater than the "Technical Specification for Water mist Fire Extinguishing System" required by the minimum spray intensity, so the system to meet the design requirements. To improve the fire-fighting efficiency and ensure reliability test, place the fire source in the middle of the tunnel. The specific layout is shown below.
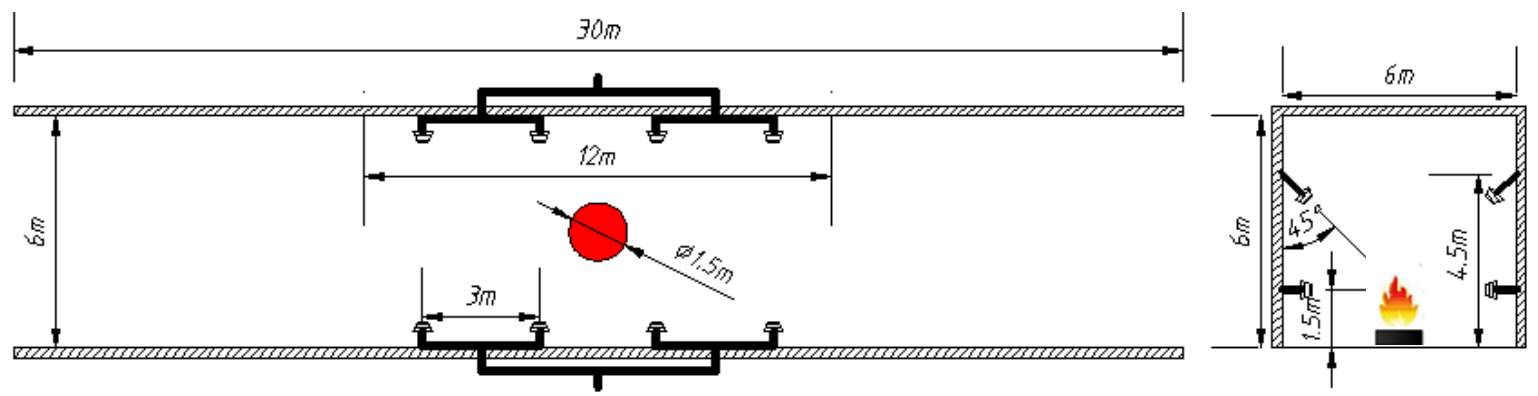

Fig. 1 Experimental Bench Layout

As the gasoline fires have typical characteristics of liquid fires, and the transport of oil items occupies an important position in rail transport, therefore, so use of $93 \#$ gasoline as a fuel. Experimental model of extinguishing liquid fire according to wheeled fire extinguishers, as shown in the following table.

Table 1 Experimental Model of Liquid Fire

\begin{tabular}{|c|c|c|c|c|c|}
\hline \multirow[b]{2}{*}{$\begin{array}{l}\text { Level } \\
\text { Code }\end{array}$} & \multirow[b]{2}{*}{$\begin{array}{c}\text { Liquid Volume } \\
(1 / 3 \text { Water }+2 / 3 \\
\text { Fuel }) \\
\text { [L] }\end{array}$} & \multicolumn{4}{|c|}{ Combustion Disk Size } \\
\hline & & $\begin{array}{c}\text { Edge } \\
\text { Diameter } \\
{[\mathrm{mm}]}\end{array}$ & $\begin{array}{c}\text { Internal } \\
\text { Depth } \pm 5 \\
{[\mathrm{~mm}]}\end{array}$ & $\begin{array}{l}\text { Minimum } \\
\text { Wall } \\
\text { Thickness } \\
{[\mathrm{mm}]}\end{array}$ & $\begin{array}{c}\text { Approximate } \\
\text { Area } \\
{\left[\mathrm{m}^{2}\right]}\end{array}$ \\
\hline$(43 B)$ & 43 & $1320 \pm 15$ & 150 & 2.5 & 1.36 \\
\hline 55 & 55 & $1480 \pm 15$ & 150 & 2.5 & 1.73 \\
\hline
\end{tabular}

According to the experimental data, the experimental model with grade code 55 is selected. The gasoline is $37 \mathrm{~L}$, the water is $18 \mathrm{~L}$, and the diameter of combustion disk is $1.5 \mathrm{~m}$.

Measurement System. As an important parameter in the process of fire development, heat release rate can not only reflect the flame release heat to the surrounding combustible materials, but also is an important indicator of the degree of injury to the personnel. In this experiment, the radiant heat flux at 
$2 \mathrm{~m}$ from the fire source is measured by the SBG0-50 radiant heat flow meter to calculate the heat release rate of the fire source. The layout is shown in the following picture.

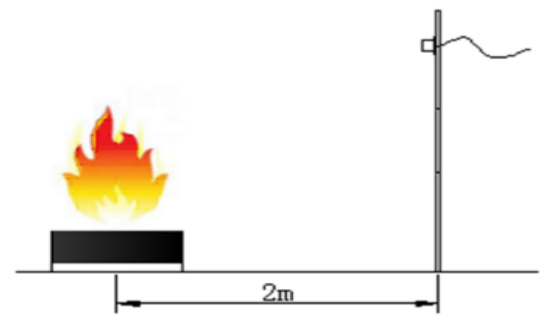

Fig. 2 Arrangement of Heat Measuring Device

Combined with the railway tunnel in the event of fire often because the tunnel top temperature is too high, there are structural damage and high voltage cable damage. In this experiment, nine K-type thermocouples are arranged in the center of the top of the tunnel to measure the temperature of the top of the tunnel. The distance between adjacent measuring points is $3 \mathrm{~m}$. The specific layout of the situation as shown below.

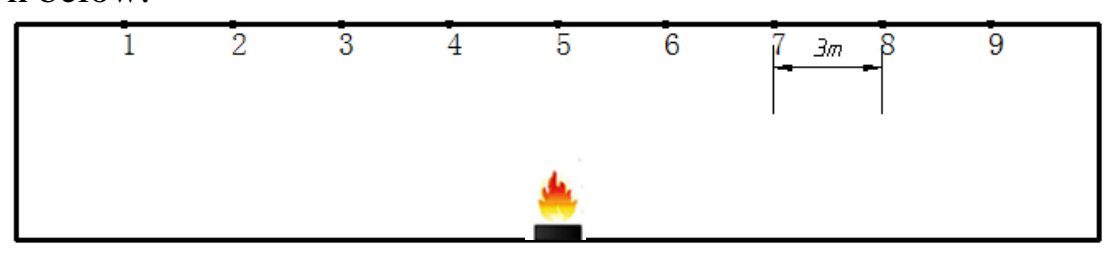

Fig. 3 Arrangement of Temperature Measuring Points

\section{Calorimetric Experiment}

Before the fire test, it is necessary to carry out the calorimetric test on the fire source, which provides an important basis for the combustion situation when the fire source does not open the fire extinguishing system and the time of opening the water mist system.

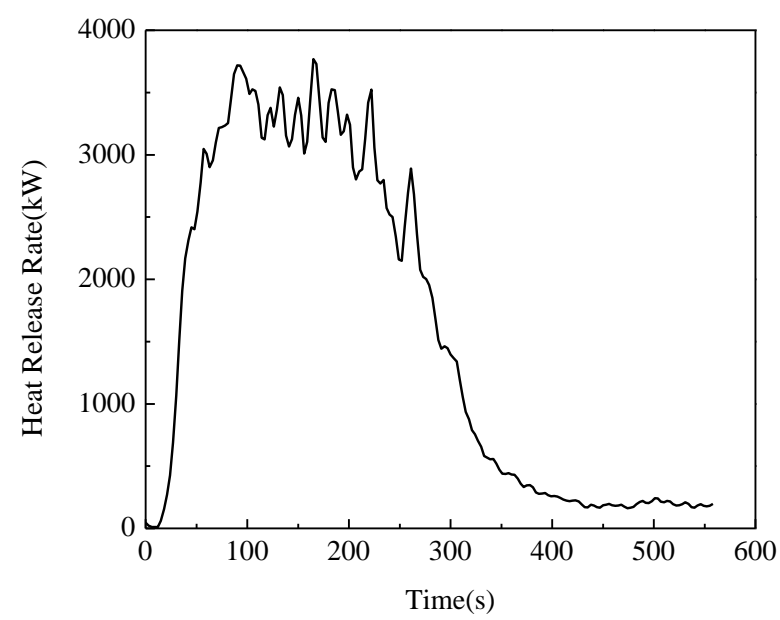

Fig. 4 The Heat Release Rate Curve when the Fire Source is Free to Develop

It can be seen from the figure that the heat release rate increases rapidly after ignition. After $30 \mathrm{~s}$, the heat release rate reached $1000 \mathrm{~kW}$, and its $\mathrm{t}^{2}$ fire [11] has a growth coefficient of $1.11 \mathrm{~kW} / \mathrm{s}^{2} .80 \mathrm{~s}$ when the heat release rate of $3400 \mathrm{~kW}$, and maintained for about 140 seconds. The heat release rate began to drop at $220 \mathrm{~s}$ and fell to around $250 \mathrm{~kW}$ in 220 seconds. The burning time is about $420 \mathrm{~s}$. Therefore, the time to open the water mist should be between 80 to $220 \mathrm{~s}$ after ignition. In order to ensure the full development of fire and experimental persuasion, it is selected to open the water mist at $120 \mathrm{~s}$ after ignition, and closing water mist should be earlier than $420 \mathrm{~s}$. 


\section{Experimental Results}

On the water mist nozzle height of $1.5 \mathrm{~m}$ and $4.5 \mathrm{~m}$ of water mist fire extinguishing system were carried out fire test. The first of fire extinguishing experiments using a nozzle height of $1.5 \mathrm{~m}$ water mist fire extinguishing system (hereinafter referred to as $1.5 \mathrm{~m}$ system). The second of fire extinguishing experiments using a nozzle height of $4.5 \mathrm{~m}$ water mist fire extinguishing system (hereinafter referred to as $4.5 \mathrm{~m}$ system).

Experimental Phenomena. Through experimental phenomena (Fig. 5 and Fig. 6), we can see that the fire has developed very rapidly after the ignition. After $120 \mathrm{~s}$ of ignition to open the water mist fire extinguishing system. Within $5 \mathrm{~s}$, two fires were well suppressed, and the fine mist gradually filled the tunnel. After closing the water mist, re-ignite the test were carried out, and none of them could be ignited.

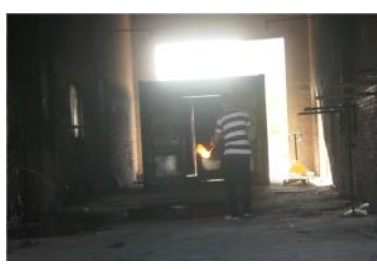

$0 \mathrm{~s}$

Ignition

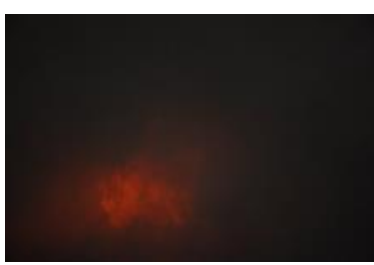

$125 \mathrm{~s}$

Burn down

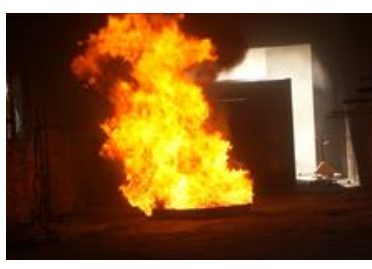

$80 \mathrm{~s}$

The fire reached its maximum

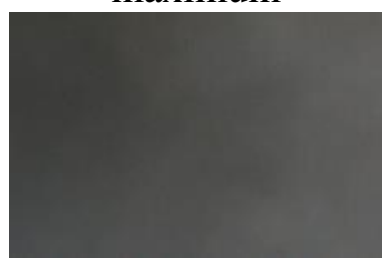

$160 \mathrm{~s}$

Water mist fills the tunnel

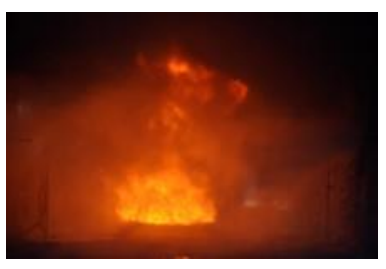

$120 \mathrm{~s}$

Water mist opening

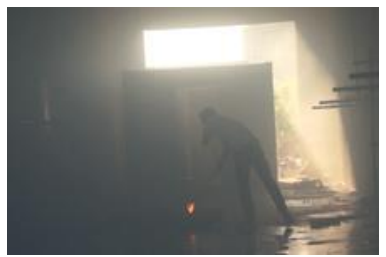

Unable to ignite again

Fig. 5 Fire Extinguishing Phenomena in $1.5 \mathrm{~m}$ System

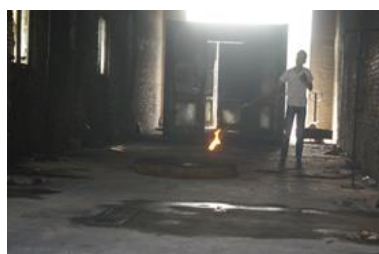

$0 \mathrm{~s}$

Ignition

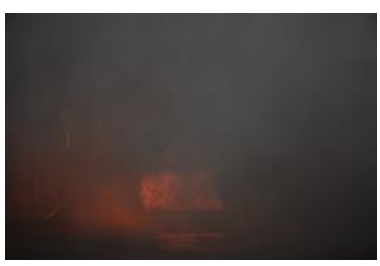

$125 \mathrm{~s}$

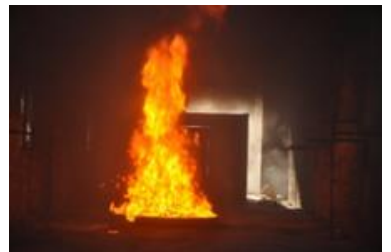

$80 \mathrm{~s}$

The fire reached its

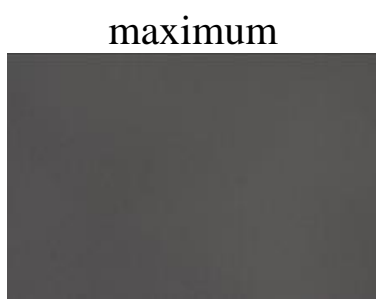

$150 \mathrm{~s}$

Burn down

\section{Water mist fills the tunnel}

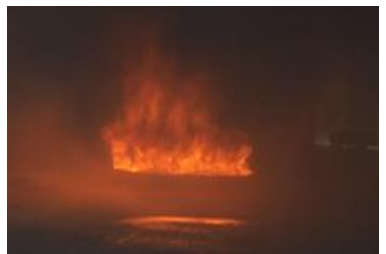

$120 \mathrm{~s}$

Water mist opening

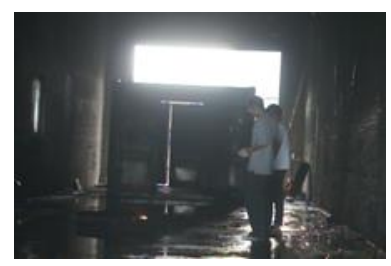

Unable to ignite again

Fig. 6 Fire Extinguishing Phenomena in $4.5 \mathrm{~m}$ System

Therefore, it can be concluded that two experiments during the opening of the water mist, the fire has been well inhibited, but the fire is still burning until the fuel burn out.

Heat Release Rate. According to the test results of the heat release rate (Fig. 7), the heat release rate increases rapidly after ignition. Before the application of water mist, the first experimental heat 
release rate of up to $3400 \mathrm{~kW}$, the second experiment up to $3600 \mathrm{~kW}$. After opening the water mist, the heat release rates of the two experiments were significantly reduced. The first experiment dropped directly to $250 \mathrm{~kW}$ in 50 seconds, while the second experiment dropped to $400 \mathrm{~kW}$ in 100 seconds.
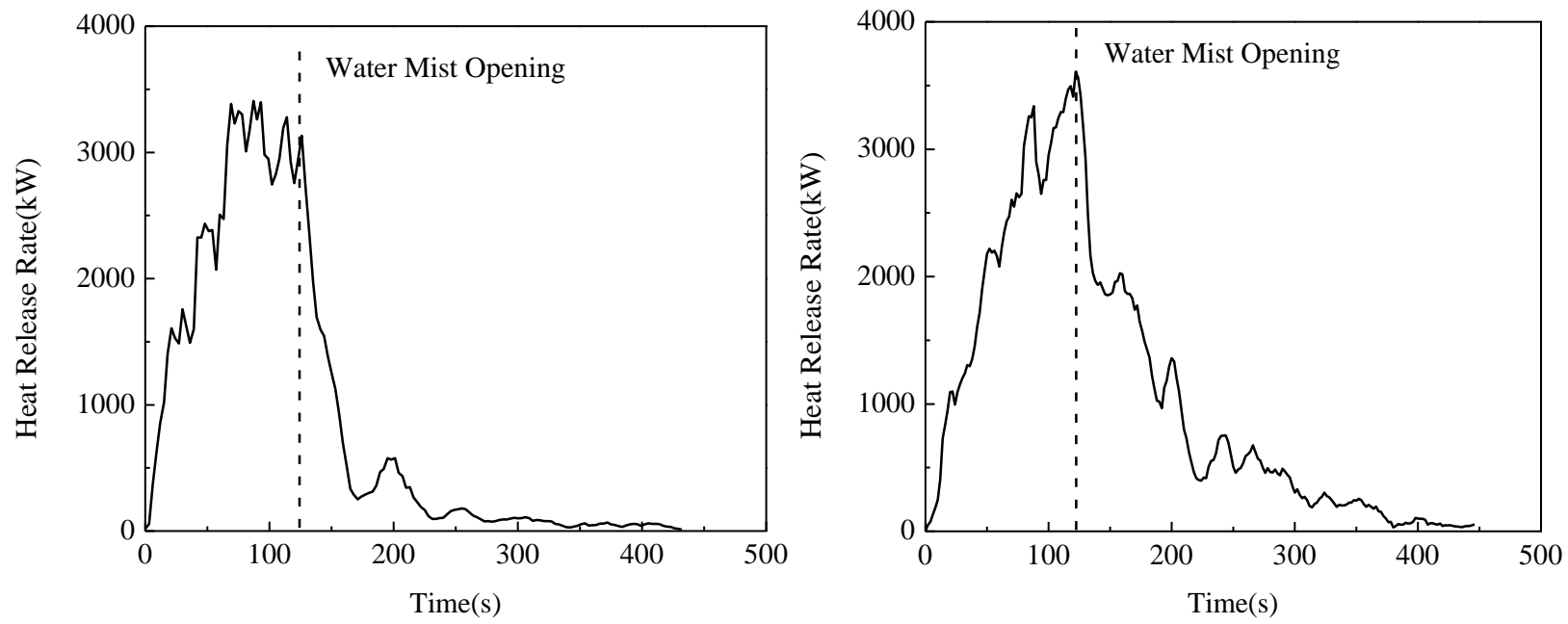

Fig. 7 Heat Release Rate Curves of the $1.5 \mathrm{~m}(\mathrm{~L})$ and $4.5 \mathrm{~m}(\mathrm{R})$ Systems

Because of the first experiment reduced more heat release rates than the second experiment at the same time after the water mist is opened. Therefore, in terms of fire suppression effect, $1.5 \mathrm{~m}$ system than the $4.5 \mathrm{~m}$ system has a better suppression of the fire effect.

Tunnel Top Temperature. According to the temperature test results (Fig. 8), we can see that the temperature of the top of the tunnel after ignition is increased rapidly in a short time. The highest temperature of the two experiments were at points 4,5 and 6 , that is, the position is above the fire source. The first experiment tunnel top temperature up to $200{ }^{\circ} \mathrm{C}$, the second experiment tunnel top temperature up to $230{ }^{\circ} \mathrm{C}$, this is mainly due to the rapid combustion of gasoline after being ignited, and the spread of high temperature smoke to the top. After the water mist is applied, there is a certain time delay. The temperature began to decrease after the first experiment delayed about $50 \mathrm{~s}$, and decreased to about $50{ }^{\circ} \mathrm{C}$ in 340 seconds. The temperature at the top of the tunnel decreased rapidly when the second experiment delayed about $10 \mathrm{~s}$, and it dropped to about $50{ }^{\circ} \mathrm{C}$ in 270 seconds.
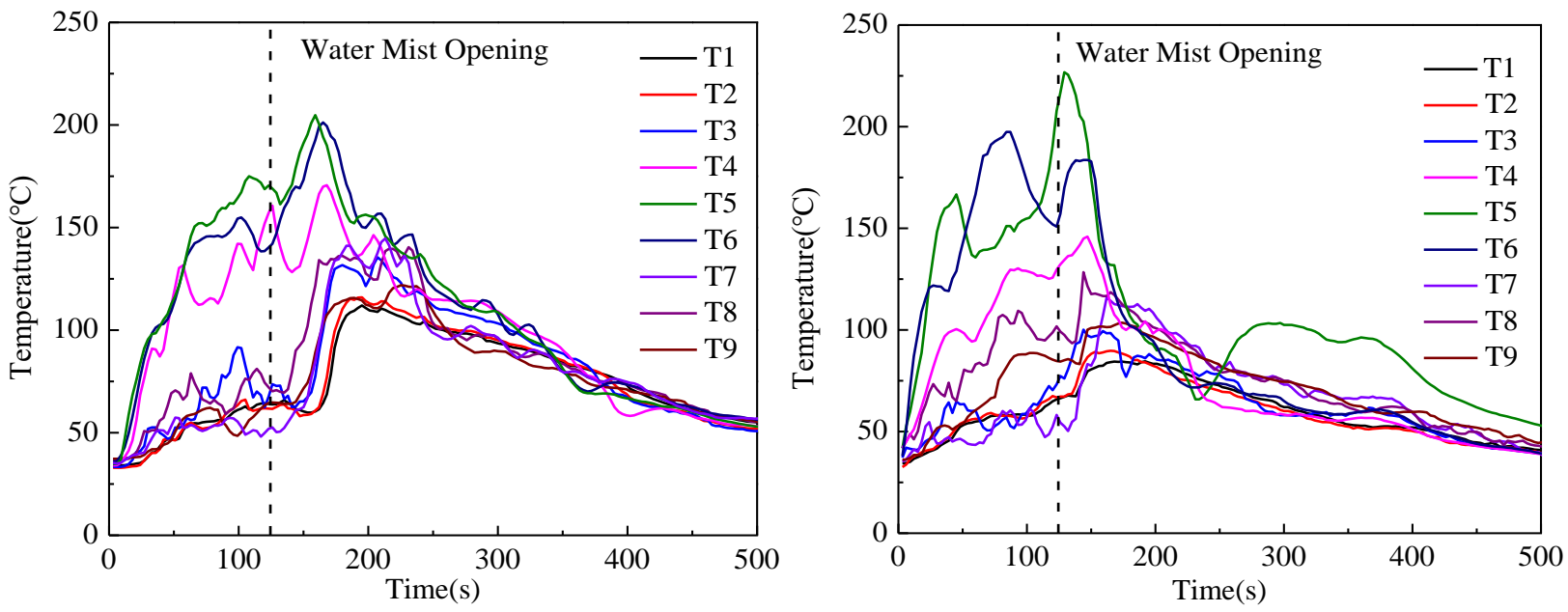

Fig. 8 Temperature Curve of the $1.5 \mathrm{~m}(\mathrm{~L})$ and $4.5 \mathrm{~m}(\mathrm{R})$ System

Because of the second experiment reduced more temperature than the first experiment at the same time after the water mist is opened. Therefore, in terms of cooling effect at the top of the tunnel, the $1.5 \mathrm{~m}$ system has a longer reaction time, and in the same time the cooling effect is not as the $4.5 \mathrm{~m}$ system. 


\section{Conclusions}

Through the experiment of influence of water mist nozzle height on fire extinguishing system in railway tunnel rescue station, leading to the following conclusion:

Water mist sprayed by the nozzle height of $1.5 \mathrm{~m}$ water mist fire extinguishing system can quickly reach the surface of combustion, and concentrated near the fire source, it can better suppress the flame and reduce the thermal radiation of the fire to the surrounding environment. While water mist sprayed by the nozzle height of $4.5 \mathrm{~m}$ water mist fire extinguishing system is mainly located in the middle part of the tunnel, although the suppression of fire is not as good as $1.5 \mathrm{~m}$ system, but the tunnel at the top of the cooling effect is more obvious.

For water mist fire extinguishing system in railway tunnel rescue station, as the water mist nozzle has a special installation method, in order to effectively extinguish the fire, the design system may need to be more stringent than the general design specification of water mist system.

\section{Acknowledgements}

This work was financially supported by National Science and Technology Support Program of "The 12th Five-Year" Plan Period, Program (2014BAK17B02), National Science and Technology Support Program of "The 12th Five-Year" Plan Period, Program (2014BAK17B03).

\section{References}

[1] Ren K, Yang L, Pu J. Numerical simulation of water mist cooling effect of extinguishing fire in typical engine room [J]. Journal of Naval University of Engineering, 2014, 26(5): 97-101.

[2] Li L. Application of high pressure water mist in archives information room [J]. Archives of China, 2017, (09): 61-63.

[3] Liu J. Study on temperature and concentration diffusion characteristics of water mist fire extinguishing liquid mist [D]. Lan Zhou Jiao Tong University, 2016.

[4] Lee S, Sun R. Characteristics of Smoke Propagation in Railway Tunnels with Rescue Station [J]. Fire Science and Engineering, 2009, 23(4): 13-18.

[5] Du W. Research progress of water mist fire suppression mechanism [J]. Fire Protection Technology and Product Information, 2013, (08): 74-76.

[6] Lal S, Gupta M, Kushari A. Suppression of pool fire in a large enclosure with water mist [J]. International Journal of Spray and Combustion Dynamics, 2013, 5(3): 181-199.

[7] Li Y, Pu J, Zhang S. Numerical Analysis of Water mist Drop Survival Time [J]. Applied Mechanics and Materials, 2012, (178): 958-961.

[8] Wang J, Dong X. Experiment study on extinguishing shelf fires by high-pressure water mist system [J]. Journal of Thermal Science and Technology, 2011, 10(4): 351-355.

[9] Tian B, Chen M, Liu J, et al. Experimental study on the influence of fine mist on the heat release rate of oil pool [J]. Fire Science, 2015, 24 (03): 136-141.

[10] GB.50898-2013. Technical specification for water mist fire extinguishing system [S]. Beijing: Ministry of Housing and Urban-Rural Development of the People's Republic of China, 2013.

[11] Wang Z, Ni Z, Wang Z, Jiang M. Determination of the heat release rate curve of fire when designing fire [J]. Journal of Safety and Environment, 2004, (S1): 50-54. 